\title{
Effects of hydrogen sulfide on inflammation in caerulein-induced
} acute pancreatitis Jenab N Sidhapuriwala ${ }^{1}$, Siaw Wei $\mathrm{Ng}^{2}$ and Madhav Bhatia*1

Address: ${ }^{1}$ Cardiovascular Biology Research Group, Department of Pharmacology, Yong Loo Lin School of Medicine, CRC MD11, National University of Singapore 117597, Singapore, Singapore and 2University of Oxford Department of Physiology, Anatomy and Genetics Sherrington Building, Parks Road, Oxford OX1 3PT, UK

Email: Jenab N Sidhapuriwala - jenab_n_sidhapuriwala@nuhs.edu.sg; Siaw Wei Ng - swng101@hotmail.com; Madhav Bhatia* - mbhatia@nus.edu.sg

* Corresponding author

Published: 30 December 2009

Journal of Inflammation 2009, 6:35 doi:10.1 186/1476-9255-6-35
Received: 13 August 2009

Accepted: 30 December 2009

This article is available from: http://www.journal-inflammation.com/content/6/1/35

(c) 2009 Sidhapuriwala et al; licensee BioMed Central Ltd.

This is an Open Access article distributed under the terms of the Creative Commons Attribution License (http://creativecommons.org/licenses/by/2.0), which permits unrestricted use, distribution, and reproduction in any medium, provided the original work is properly cited.

\begin{abstract}
Background: Hydrogen sulfide $\left(\mathrm{H}_{2} \mathrm{~S}\right)$, a gaseous mediator plays an important role in a wide range of physiological and pathological processes. $\mathrm{H}_{2} \mathrm{~S}$ has been extensively studied for its various roles in cardiovascular and neurological disorders. However, the role of $\mathrm{H}_{2} \mathrm{~S}$ in inflammation is still controversial. The current study was aimed to investigate the therapeutic potential of sodium hydrosulfide $(\mathrm{NaHS})$, an $\mathrm{H}_{2} \mathrm{~S}$ donor in in vivo model of acute pancreatitis in mice.
\end{abstract}

Methods: Acute pancreatitis was induced in mice by hourly caerulein injections $(50 \mu \mathrm{g} / \mathrm{kg})$ for 10 hours. Mice were treated with different dosages of NaHS $(5 \mathrm{mg} / \mathrm{kg}, 10 \mathrm{mg} / \mathrm{kg}$ or $15 \mathrm{mg} / \mathrm{kg})$ or with vehicle, distilled water (DW). NaHS or DW was administered I h before induction of pancreatitis. Mice were sacrificed I $\mathrm{h}$ after the last caerulein injection. Blood, pancreas and lung tissues were collected and were processed to measure the plasma amylase, myeloperoxidase (MPO) activities in pancreas and lung and chemokines and adhesion molecules in pancreas and lung.

Results: It was revealed that significant reduction of inflammation, both in pancreas and lung was associated with NaHS $10 \mathrm{mg} / \mathrm{kg}$. Further the anti-inflammatory effects of NaHS $10 \mathrm{mg} / \mathrm{kg}$ were associated with reduction of pancreatic and pulmonary inflammatory chemokines and adhesion molecules. NaHS $5 \mathrm{mg} / \mathrm{kg}$ did not cause significant improvement on inflammation in pancreas and associated lung injury and $\mathrm{NaHS} 15 \mathrm{mg} / \mathrm{kg}$ did not further enhance the beneficial effects seen with $\mathrm{NaHS} 10 \mathrm{mg} / \mathrm{kg}$.

Conclusion: In conclusion, these data provide evidence for anti-inflammatory effects of $\mathrm{H}_{2} \mathrm{~S}$ based on its dosage used.

\section{Background}

Hydrogen sulphide $\left(\mathrm{H}_{2} \mathrm{~S}\right)$ a novel gaseous messenger, is synthesized endogenously from L-cysteine by two pyridoxal-5'-phosphate-dependent enzymes, cystathionine $\beta$ synthetase (CBS, EC4.2.1.22) and cystathionine $\gamma$-lyase (CSE, EC4.4.1.1). Both CBS and CSE are widely distrib- uted in tissues. However, CBS is the predominant source of $\mathrm{H}_{2} \mathrm{~S}$ in the central nervous system whereas CSE is the major $\mathrm{H}_{2} \mathrm{~S}$-producing enzyme in the cardiovascular system. $\mathrm{H}_{2} \mathrm{~S}$ dilates blood vessels and relaxes gastrointestinal smooth muscles by opening muscle $\mathrm{K}_{\mathrm{ATP}}$ channels and promotes hippocampal long-term potentiation by 
enhancing the sensitivity of N-methyl-D-aspartate receptors to glutamate $[1,2]$.

Since the discovery of endogenous $\mathrm{H}_{2} \mathrm{~S}$, many studies have been performed to understand the physiologic and pathologic roles of this gas and numerous animal studies have shown its beneficial effects especially in cardiovascular disorders [2]. However the role of $\mathrm{H}_{2} \mathrm{~S}$ in inflammation is only recently beginning to emerge and the exact role of $\mathrm{H}_{2} \mathrm{~S}$ in inflammation is still not very clearly understood. Research studies have shown pro-inflammatory effects of $\mathrm{H}_{2} \mathrm{~S}$ in various models of inflammation. In those models of inflammation plasma $\mathrm{H}_{2} \mathrm{~S}$ level, tissue $\mathrm{H}_{2} \mathrm{~S}$ synthesizing enzyme activity and CSE expression were increased and inhibition of $\mathrm{H}_{2} \mathrm{~S}$ synthesis by DL-propargylglycine (PAG) treatments reduced the inflammation [3-8]. In addition, some studies have also reported antiinflammatory effects of $\mathrm{H}_{2} \mathrm{~S}$. Treatments with either $\mathrm{H}_{2} \mathrm{~S}$ releasing non steroidal anti-inflammatory drugs (e.g. sdiclofenac, ATB-429) or with $\mathrm{H}_{2} \mathrm{~S}$ donors (e.g. sodium hydrosulfide, Lawesson's reagent or N-acetylcysteine) have demonstrated anti-inflammatory activity in various models of inflammation [9-15]. Recent studies have also shown biphasic dose response of $\mathrm{H}_{2} \mathrm{~S}$ in inflammation. In myocardial ischemia reperfusion injury, treatment with different doses of $\mathrm{H}_{2} \mathrm{~S}$ ranging from $(10-500 \mu \mathrm{g} / \mathrm{kg})$ revealed $U$ shaped dose response curve. In this study, significant reduction of infarct size was observed in mice received $50 \mu \mathrm{g} / \mathrm{kg}[16]$. In another study of myocardial ischemia reperfusion injury, similar effect of $\mathrm{H}_{2} \mathrm{~S}$ was observed. Post conditioning with exogenous sodium hydrosulfide (NaHS) treatment $(0.1$ to $10 \mu \mathrm{M})$ produced a concentration-dependent limitation of infarct. However, NaHS $(100 \mu \mathrm{M})$ did not decrease the infarct size [17].

In the present study we investigated therapeutic potential of sodium hydrosulfide ( $\mathrm{NaHS}$ ), an $\mathrm{H}_{2} \mathrm{~S}$ donor in in vivo model of acute pancreatitis in mice.

\section{Methods}

\section{Experimental procedures}

All animal experiments were approved by the Animal Ethic Committee of National University of Singapore and were carried out in accordance with established International Guiding Principles for Animal Research). Swiss mice (male, 20-25 g) were used and maintained in the Animal Housing Unit in an environment with controlled temperature $\left(21-24^{\circ} \mathrm{C}\right)$ and lighting $(12: 12 \mathrm{~h}$ light-darkness cycle). Standard laboratory chow and drinking water were provided ad libitum. A period of at least 2 days was allowed for the animals to acclimatize before any experimental procedures were undertaken.

\section{Induction of acute pancreatitis}

Caerulein was obtained from Bachem (Bubendorf, Switzerland) and NaHS was obtained from Sigma-Aldrich (USA). Mice were randomly assigned to control or experimental groups using 10 animals for each group. Animals were given hourly intraperitoneal (i.p.) injections of normal saline (saline control group) or saline containing caerulein $(50 \mu \mathrm{g} / \mathrm{kg})$ over 10 hours [4,10]. Groups of animal were treated either with different doses of NaHS (5 $\mathrm{mg} / \mathrm{kg}, 10 \mathrm{mg} / \mathrm{kg}$ or $15 \mathrm{mg} / \mathrm{kg}$ ) dissolved in distilled water (DW), or with only DW (vehicle). NaHS or DW was given i.p. one hour before the first caerulein injection. One hour after the last caerulein injection animals were sacrificed by an i.p. injection of a lethal dose of pentobarbital (50 mg/ kg: Nembutal, CEVA Sante Animale, Naaldwijk, Netherlands). Blood, pancreas and lung tissues were collected. Harvested heparinized blood was centrifuged $(10,000$ $\mathrm{rpm}, 10 \mathrm{~min}, 4^{\circ} \mathrm{C}$ ) and the plasma was aspirated and stored at $-80^{\circ} \mathrm{C}$ for subsequent detection of plasma amylase. Samples of pancreas and lung were weighed, snap frozen in liquid nitrogen and then stored at $-80^{\circ} \mathrm{C}$ for subsequent measurement of tissue myeloperoxidase (MPO) activities, chemokines and adhesion molecules as described in detail below. Parts of the pancreas and lung were also fixed in $10 \% \mathrm{vol} / \mathrm{vol}$ neutral phosphate-buffered formalin for more than $48 \mathrm{~h}$ and then were processed for histology.

\section{Amylase estimation}

Plasma amylase activity was measured using a kinetic spectrophotometric assay. Plasma samples were incubated with the Amylase reagent (Sigma, St. Louis, Mo) for 2 min at $37^{\circ} \mathrm{C}$, and absorbance was measured every minute for the subsequent $2 \mathrm{~min}$ at $405 \mathrm{~nm}$ using manufacturers' instructions $[4,10]$. The resulting change in absorbance was used to calculate the amylase activity.

\section{MPO estimation}

Inflammatory cells sequestration in pancreas and lung were quantified by measuring tissue MPO activity $[4,10]$. Tissue samples were thawed, homogenized in $20 \mathrm{mM}$ phosphate buffer ( $\mathrm{pH} 7.4)$, centrifuged (13,000 rpm, 10 min, 4-C), and the resulting pellet resuspended in $50 \mathrm{mM}$ phosphate buffer ( $\mathrm{pH}$ 6.0) containing $0.5 \% \mathrm{wt} / \mathrm{vol}$ hexadecyltrimethylammonium bromide (Sigma). The suspension was subjected to four cycles of freezing and thawing and further disrupted by sonication (40 s). The sample was then centrifuged $(13,000 \mathrm{rpm}, 5 \mathrm{~min}, 4-\mathrm{C})$, and the supernatant was used for the MPO assay. The sample was mixed with equal volume of 1-component tetramethylbenzidine (TMB) substrate (Sureblue), incubated for a fixed time, and then terminated by equal volume of $2 \mathrm{~N}$ $\mathrm{H}_{2} \mathrm{SO} 4$. The absorbance was measured at $450 \mathrm{~nm}$ and corrected for the calculated DNA [18] of the tissue sample. 
Results were expressed as enzyme activity (fold increase over corresponding saline injected control groups).

\section{Morphological examination}

Paraffin-embedded pancreas and lung samples were sectioned $(5 \mu \mathrm{m})$, stained with hematoxylin/eosin ( $\mathrm{H}$ and $\mathrm{E})$ and were examined with light microscopy.

\section{Enzyme-linked immunosorbent assay (ELISA) analysis of chemokines and adhesion molecules}

The levels of chemokines (CCL2, CCL3 and CXCL1) and adhesion molecules (E- and P-selectins, ICAM-1, and VCAM-1) were measured in pancreas and lung tissue homogenate by a sandwich ELISA using DuoSet ELISA kits. Briefly, an anti-chemokine//adhesion molecule primary antibodies were coated onto 96- well ELISA plates and incubated overnight at room temperature. Samples and standards were added to the wells and incubated for $2 \mathrm{~h}$, the wells were washed, and a biotinylated goat antimouse chemokine/adhesion molecule antibodies were added for $2 \mathrm{~h}$. Plates were washed again, and streptavidin antibodies conjugated to HRP were added for $20 \mathrm{~min}$. After a further wash, TMB was added for color development, and the reaction was terminated with $2 \mathrm{~N} \mathrm{H}_{2} \mathrm{SO} 4$. Absorbance was measured at $450 \mathrm{~nm}$. Sample concentration was estimated from the standard curve. The sample concentration was then corrected for the DNA content of the tissue [18].

\section{Statistical analysis}

All values were expressed as mean \pm S.E.M. The significance of changes was evaluated by using ANOVA when comparing three or more groups and Tukey and/or LSD method were used as a post hoc test for comparison among different groups. A $P$ value of $<0.05$ was considered to indicate a significant difference.

\section{Results}

Effect of different dosages of NaHS on plasma amylase in caerulein-induced acute pancreatitis

In our initial studies, groups of mice $(n=10)$ were treated with different dosages of NaHS (N5 mg/kg, N10 mg/kg and $\mathrm{N} 15 \mathrm{mg} / \mathrm{kg}$ ). NaHS was administered $1 \mathrm{~h}$ before the caerulein induced pancreatitis. Effects of NaHS were compared with the group of mice $(n=10)$ treated with only DW (vehicle) $1 \mathrm{~h}$ before the caerulein induced pancreatitis. As shown in Fig. 1, mice pretreated with vehicle or with NaHS followed by hourly caerulein injections, pancreatitis was manifested by significant rise in plasma amylase activity compared to mice injected with hourly saline only $(P<0.05)$. However within the NaHS group, significant reduction of plasma amylase compared to vehicle pretreated mice was not associated with mice received NaHS either $5 \mathrm{mg} / \mathrm{kg}$ or $15 \mathrm{mg} / \mathrm{kg}$ and a small but significant reduction of plasma amylase activity was observed only in mice received NaHS $10 \mathrm{mg} / \mathrm{kg}(\mathrm{P}<0.05)$.

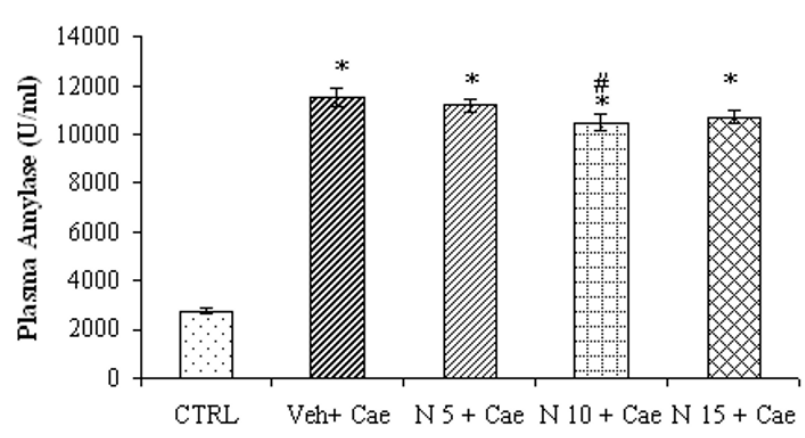

\section{Figure I}

Effect of NaHS treatment on plasma amylase activity. Acute pancreatitis was induced by intraperitoneal administration of caerulein $((50 \mu \mathrm{g} / \mathrm{kg}$, hourly for $10 \mathrm{~h})$. Column labeled 'CTRL' refers to plasma amylase activity in mice injected intraperitoneal saline (not caerulein) as control. Column labeled 'Veh+Cae', 'N5+Cae', 'NI0+Cae', 'NI5+Cae' refers pretreatment with vehicle (DW) or different dosages of $\mathrm{NaHS}(5 \mathrm{mg} / \mathrm{kg}, 10 \mathrm{mg} / \mathrm{kg}$ or $15 \mathrm{mg} / \mathrm{kg}$ respectively) administered intraperitoneal I $\mathrm{h}$ before the first injection of caerulein. Results shown are the mean \pm SEM for $8-10$ animals in each group. Asterisk (*): $\mathrm{P}<0.05$ c.f. CTRL group. Asterisk (\#): P < 0.05 c.f. (Veh + Cae) group. Abbreviations used: CTRL: Control; Cae: Caerulein; Veh: Vehicle; N: NaHS.

\section{Effect of different dosages of NaHS on pancreas MPO in caerulein-induced acute pancreatitis}

Further pancreatic injury was assessed by measuring pancreatic myeloperoxidase (MPO) activity and histology. Measurement of MPO enzyme which is located in azurophile granules of neutrophils and monocytes reflects inflammatory cells infiltration in tissue. There was a significant MPO increase in mice received vehicle/or various dosages of NaHS compared to saline CTRL group (Fig. 2A). However within the NaHS treated groups, only mice pretreated with NaHS $10 \mathrm{mg} / \mathrm{kg}$ had significant reduction of MPO activity as compared with vehicle treated mice (Fig. 2A). Further histological examination of pancreas sections of vehicle pre-treated mice show clear evidence of oedema, destruction of histoarchitecture of the acini and infiltration of inflammatory cells (Fig. 2B, ii). However within the NaHS groups (Fig. 2B, iii, iv and 2B, v) mice received NaHS $10 \mathrm{mg} / \mathrm{kg}$ had a significant reduction of edema and inflammatory cells compared to vehicle pretreated mice (Fig. 2B, iv).

\section{Effect of different dosages of NaHS on acute pancreatitis- associated lung injury}

Acute pancreatitis, in mice pretreated with DW, followed by 10 hourly injections of caerulein $(50 \mu \mathrm{g} / \mathrm{kg})$ was associated with lung injury. As shown in Fig. 3A caeruleininduced acute pancreatitis was associated with a significant rise in lung MPO activity, indicating the presence of sequestered inflammatory cells. Histological examination 


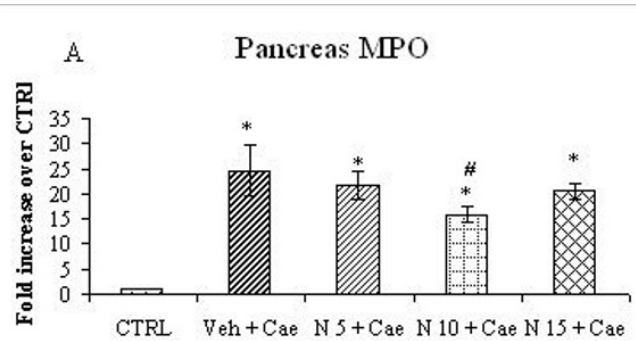

B

Pancreas Histology
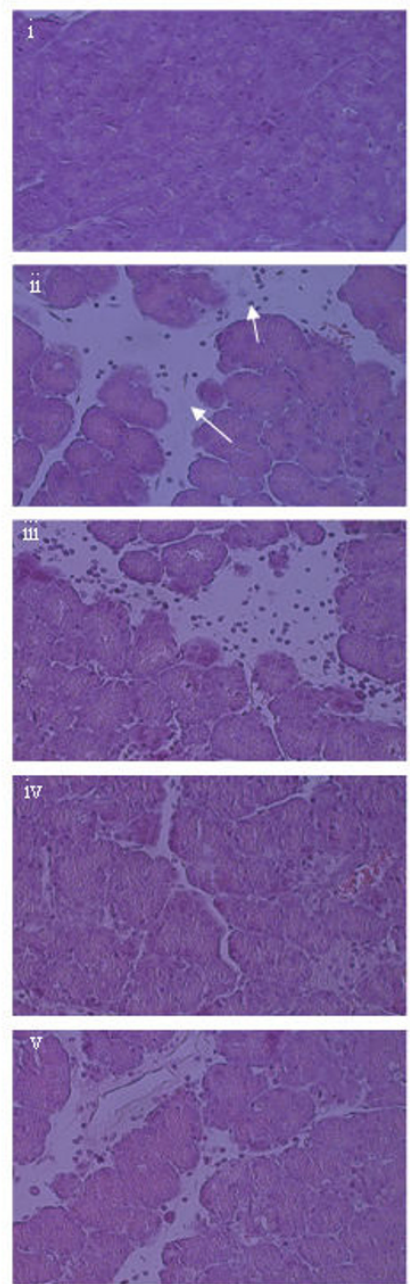

Figure 2

A: Effect of NaHS treatment on pancreatic myeloperoxidase (MPO). Acute pancreatitis was induced by intraperitoneal administration of caerulein $((50 \mu \mathrm{g} / \mathrm{kg}$ hourly, for $10 \mathrm{~h})$. Column labeled 'CTRL' refers to pancreas MPO activity in mice injected intraperitoneal saline (not caerulein) as control. Column labeled 'Veh+Cae', 'N5+Cae', 'NI0+Cae', 'NI5+Cae' refers pretreatment with vehicle or different dosages of NaHS $(5 \mathrm{mg} / \mathrm{kg}, 10 \mathrm{mg} / \mathrm{kg}$ or $15 \mathrm{mg} / \mathrm{kg}$ respectively) administered intraperitoneal I $\mathrm{h}$ before the first injection of caerulein. Results shown are the mean \pm SEM for $8-10$ animals in each group. Asterisk (*): P < 0.05 c.f. CTRL group. Asterisk (\#): P < 0.05 c.f. (Veh + Cae) group. Abbreviations used: CTRL: Control; Cae: Caerulein; Veh: Vehicle; N: NaHS. B. Pancreas histology: i, Control (saline injected) pancreas; ii, caerulein-induced pancreatitis pretreated with DW (vehicle) only; arrow showing oedema, and infiltration of inflammatory cells. iii, pretreated with $\mathrm{NaHS}(5 \mathrm{mg} / \mathrm{kg})$;iv, pretreated with NaHS (10 mg/kg); v, pretreated with NaHS (I $5 \mathrm{mg} / \mathrm{kg})$. 


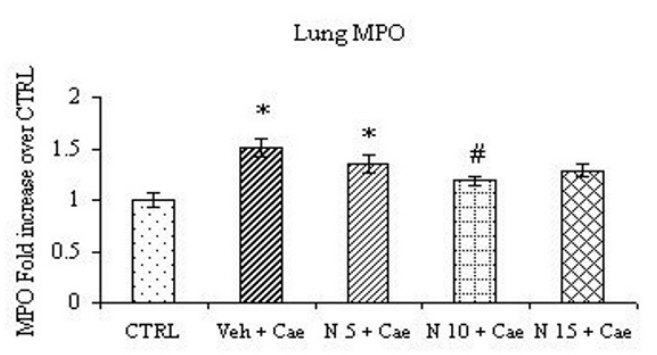

B
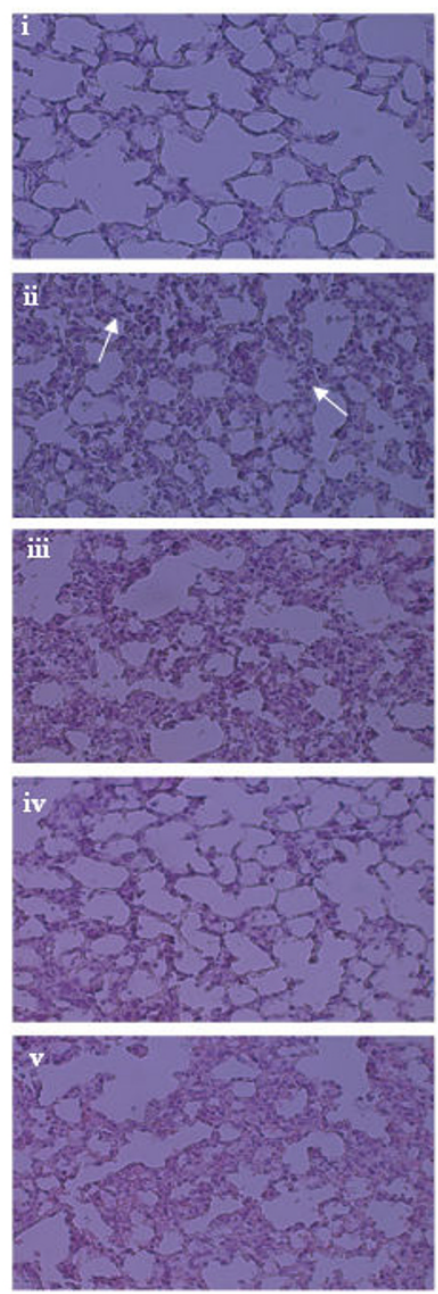

\section{Figure 3}

Effect of NaHS treatment on pancreatitis associated lung injury in acute pancreatitis. A. MPO activity in lung. Acute pancreatitis was induced by intraperitoneal administration of caerulein $((50 \mu \mathrm{g} / \mathrm{kg}$ hourly, for $10 \mathrm{~h})$. Column labeled 'CTRL' refers to lung MPO activity in mice injected intraperitoneal saline (not caerulein) as control. Column labeled 'Veh+Cae', 'N5+Cae', 'NI0+Cae', 'NI5+Cae' refers pretreatment with vehicle or different dosages of NaHS $(5 \mathrm{mg} / \mathrm{kg}, 10 \mathrm{mg} / \mathrm{kg}$ or $15 \mathrm{mg} /$ $\mathrm{kg}$ respectively) administered intraperitoneal I $\mathrm{h}$ before the first injection of caerulein. Results shown are the mean \pm SEM for 8-10 animals in each group. Asterisk (*): P $<0.05$ c.f. control (saline) group. Asterisk (\#): $\mathrm{P}<0.05$ c.f. (Veh + Cae) group. Abbreviations used: CTRL: Control; Cae: Caerulein; Veh: Vehicle; N: NaHS. B. Lung Histology: i, Lung section from control (saline injected) animal; ii, Lung section from caerulein-induced pancreatitis pretreated with DW (vehicle) only; arrow showing alveolar thickening and inflammatory cells infiltration. iii, pretreated with $\mathrm{NaHS}(5 \mathrm{mg} / \mathrm{kg})$;iv, pretreated with $\mathrm{NaHS}$ (I0 mg/kg); v, pretreated with $\mathrm{NaHS}$ (I5 mg/kg). 
of lung sections further confirmed evidence of lung injury in acute pancreatitis as evidenced by alveolar thickening and abundance inflammatory cells infiltration (Fig. 3B, ii). However group of mice pretreated with NaHS $10 \mathrm{mg} /$ $\mathrm{kg}$ had significant reduction of cellular infiltration as evidenced by lung MPO (Fig. 3A) and lung histology (Fig. $3 \mathrm{~B}, \mathrm{iv})$, while such protection was not seen in groups of mice pretreated with NaHS $5 \mathrm{mg} / \mathrm{kg}$ or $15 \mathrm{mg} / \mathrm{kg}$ (Fig. 3A and Fig 3B, iii and v). Thus, treatment with NaHS10 mg/ $\mathrm{kg}$, but not with $5 \mathrm{mg} / \mathrm{kg}$ or $15 \mathrm{mg} / \mathrm{kg}$ resulted in a marked reduction in the severity of pancreatitis as well associated lung injury.

\section{Effect of NaHS $10 \mathrm{mg} / \mathrm{kg}$ on pancreatic and pulmonary chemokines}

Chemokines, well known for their potent leukocyte-activating properties have been shown to be involved in the pathophysiological process of experimental acute pancreatitis. Based on our initial data with different dosages of NaHS, we decided to see if reduction of pancreatic and pulmonary inflammation with NaHS $10 \mathrm{mg} / \mathrm{kg}$ has any effect on chemokines and adhesion molecules levels in pancreas and lung. As expected chemokines, Chemokine (C-C motif) Ligand 2 (CCL2), Chemokine (C-C motif) Ligand 3 (CCL3) and Chemokine (C-X-C motif) Ligand 1 (CXCL1) were significantly increased in pancreas as well as lung tissue (Fig 4: A, B and 4C) in vehicle treated group. However NaHS $10 \mathrm{mg} / \mathrm{kg}$ treatment significantly reduced all pancreatic chemokines and pulmonary chemokines except pulmonary CCL3 (Fig 4: A, B and 4C).

\section{Effect of NaHS $10 \mathrm{mg} / \mathrm{kg}$ on pancreatic and pulmonary cell adhesion molecules}

Pancreatic and pulmonary cell adhesion molecules Eselectin (endothelial), P-selectin (platelet), Intercellular Cell Adhesion Molecule -1 (ICAM-1) and Vascular Cell Adhesion Molecule-1 (VCAM-1) were measured by ELISA. They were significantly increased in both pancreas and lung tissue (Fig 5: A, B, C and 5D) of mice pretreated with vehicle, while NaHS $10 \mathrm{mg} / \mathrm{kg}$ significantly reduced all pancreatic and pulmonary adhesion molecules except pulmonary E-selectin (Fig 5: A, B, C and 5D).

\section{Discussion}

Hydrogen sulfide, like nitric oxide ( $\mathrm{NO}$ ) and carbon monoxide (CO) is a biological active gas of interest to pharmacologist. Several recent publications have shown its physiological/pathological contribution mainly in cardiovascular system (CVS) and central nervous system (CNS) and its therapeutic potential in CVS and CNS disorders $[1,2]$. However, its precise role and therapeutic application in inflammatory disorders is still controversial. Exogenous administrations of $\mathrm{H}_{2} \mathrm{~S}$ have shown either proinflammatory or anti-inflammatory effects depending on its formula, dose and disease model [5,6,9-15]. Recent studies have also shown that exogenous NaHS administration exerted biphasic therapeutic response $[16,17]$. The present study was aimed to investigate the therapeutic potential of exogenous $\mathrm{NaHS}\left(\mathrm{H}_{2} \mathrm{~S}\right.$ donor) on caeruleininduced acute pancreatitis. In our initial experiment when the mice were treated with different dosages of NaHS (5 $\mathrm{mg} / \mathrm{kg}, 10 \mathrm{mg} / \mathrm{kg}$ and $15 \mathrm{mg} / \mathrm{kg}$ ) $1 \mathrm{~h}$ before caeruleininduced acute pancreatitis, it was revealed that there was a dose dependent reduction of plasma amylase (Fig. 1), pancreatic inflammation as evidenced by pancreas MPO and histology (Fig. 2A and 2B) and pulmonary inflammation, as evidenced by lung MPO and histology (Fig. 3A and $2 \mathrm{~B}$ ) and a significant reduction of inflammation was seen only in mice pretreated with NaHS $10 \mathrm{mg} / \mathrm{kg}$ (Fig. 1, Fig. 2A and 2B iv, Fig. 3A and 3B iv). NaHS $15 \mathrm{mg} / \mathrm{kg}$ treatment did not have any additional beneficial effect as seen with $10 \mathrm{mg} / \mathrm{kg}$, and on contrary there is a trend towards increased inflammation as evidenced by pancreas and lung MPO and histology (Fig. 2A and 2B v, Fig. 3A and 3B $v)$. Further in a separate experiment, mice treated with NaHS $20 \mathrm{mg} / \mathrm{kg}$ dose, was associated with increase mortality (experimental observation). Thus, there is a dose dependent effect of NaHS but doses $15 \mathrm{mg} / \mathrm{kg}$ and more are associated with toxic effects. Similar findings were also observed by other group albeit in different models. Treatment with $\mathrm{H}_{2} \mathrm{~S}$ donor, $\mathrm{Na}_{2} \mathrm{~S}$ in doses of $(10-500 \mu \mathrm{g} / \mathrm{kg})$ at the time of reperfusion and study of infarct size per areaat-risk (INF/AAR) revealed a U-shaped dose-response curve. Mice receiving $50 \mu \mathrm{g} / \mathrm{kg}$ displayed significant reduction in infarct size. However there is increase in ratio of INF/AAR when mice received $100 \mu \mathrm{g} / \mathrm{kg}$ or $500 \mu \mathrm{g} / \mathrm{kg}$ [16]. Similarly in another study of ischemia-reperfusion injury low physiological concentration NaHS (0.1-10 $\mu \mathrm{M})$ reduced the infarct size in a dose-dependent manner. However high concentrate $100 \mu \mathrm{M}$ NaHS increased the infarct size [17]. Although both these models are very different from our model, similar to our study treatment with different dosages of $\mathrm{H}_{2} \mathrm{~S}$ donors $\mathrm{Na}_{2} \mathrm{~S}$ or NaHS, resulted in dose dependent reduction of infarct size or inflammation and further increasing dose was not beneficial at all. The narrow therapeutic window seen with our results could be due to sudden release of $\mathrm{H}_{2} \mathrm{~S}$ from $\mathrm{H}_{2} \mathrm{~S}$ donor like NaHS. NaHS is water soluble, resulting in instant release of $\mathrm{H}_{2} \mathrm{~S}$ upon injection and causing its toxic effects.

Recruitment of various inflammatory cells like neutrophils, monocytes and macrophages to the inflamed/ injured tissues is mediated by chemokines. Chemokines are a group of low-molecular-weight (8-10 kDa) polypeptides and are the key components of immune surveillance [19]. We further investigated whether reduction of inflammatory cells infiltration in pancreas and lung was associated with any changes in chemokines. We investigated CC chemokines such as CCL2 and CCL3 and CXC chemok- 


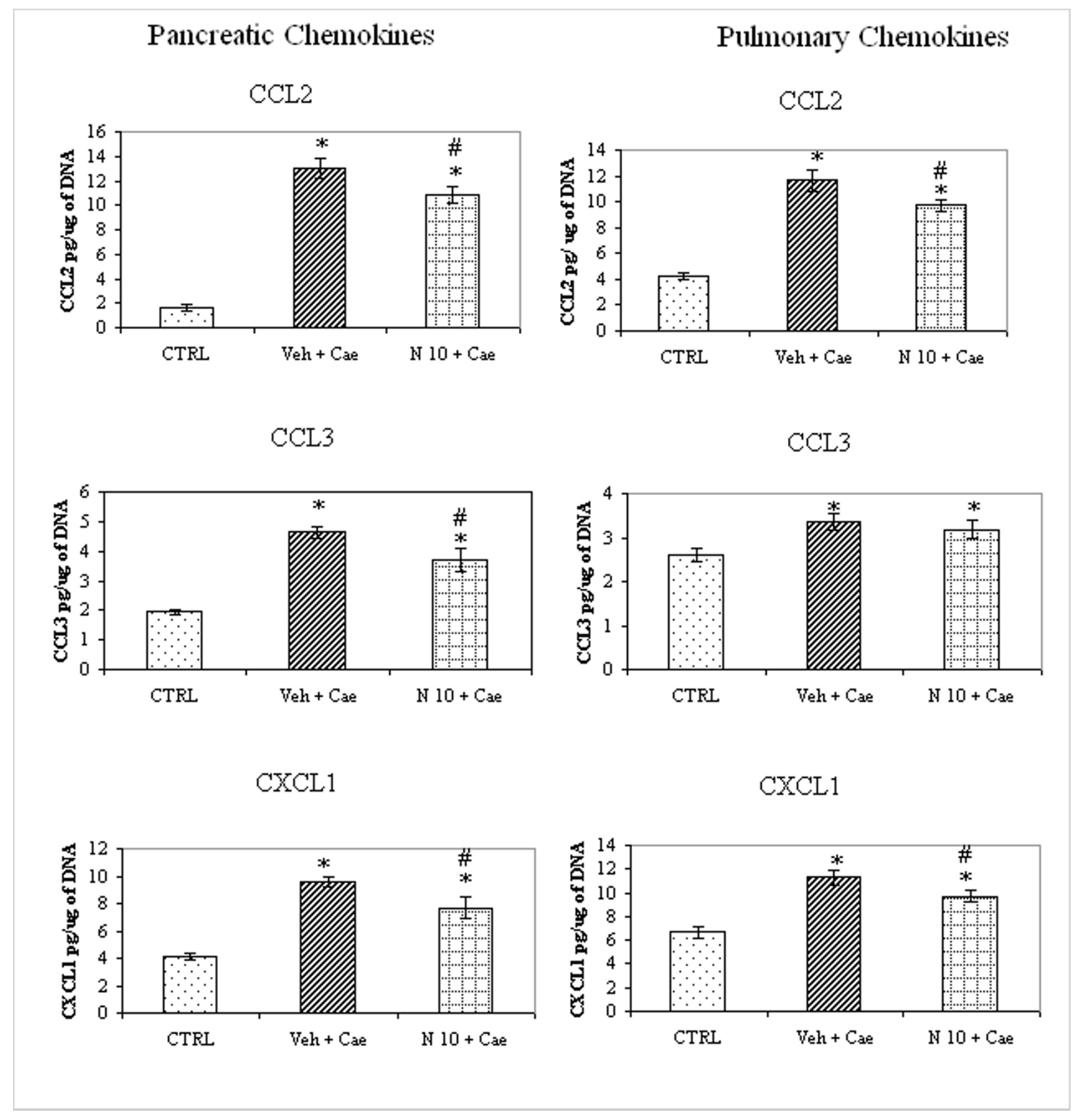

\section{Figure 4}

Effect of NaHS treatment on pancreatic and pulmonary chemokines in acute pancreatitis. Acute pancreatitis was induced by intraperitoneal administration of caerulein $((50 \mu \mathrm{g} / \mathrm{kg}$ hourly, for $10 \mathrm{~h})$. Column labeled CTRL' refers to chemokines level in mice injected intraperitoneal saline (not caerulein) as control. Column labeled 'Veh+Cae' and 'NI0+Cae' refers pretreatment with vehicle or NaHS (10 mg/kg) administered intraperitoneal I h before the first injection of caerulein. Results shown are the mean \pm SEM for $8-10$ animals in each group. Asterisk (*): $\mathrm{P}<0.05$ c.f. control (saline) group. Asterisk (\#): $\mathrm{P}<$ 0.05 c.f. (Veh + Cae) group. Abbreviations used: CTRL: Control; Cae: Caerulein; Veh: Vehicle; N: NaHS. 
Pancreatic adhesion molecules

E-selectin

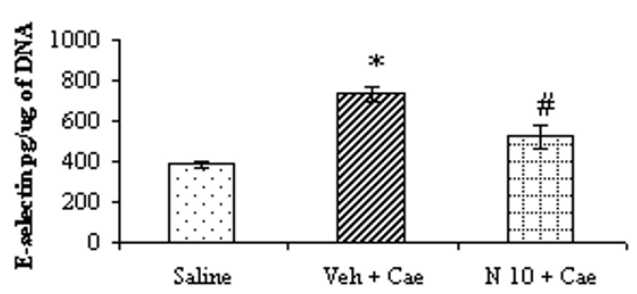

P-selectin

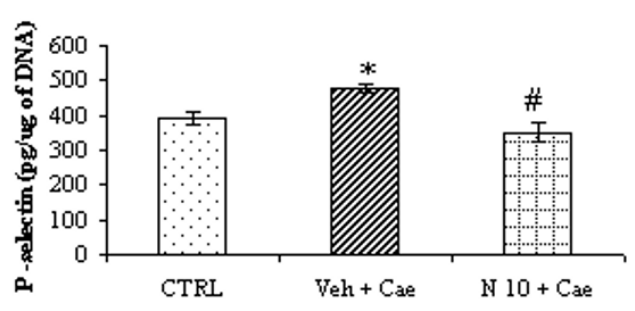

ICAM-1

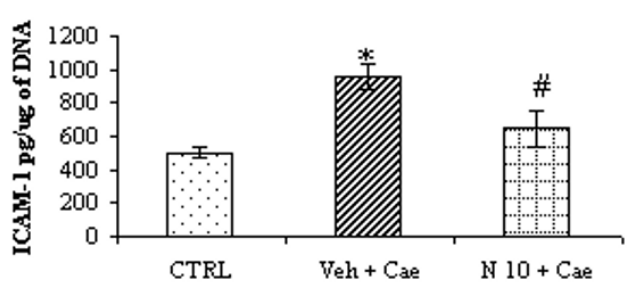

VCAM-1

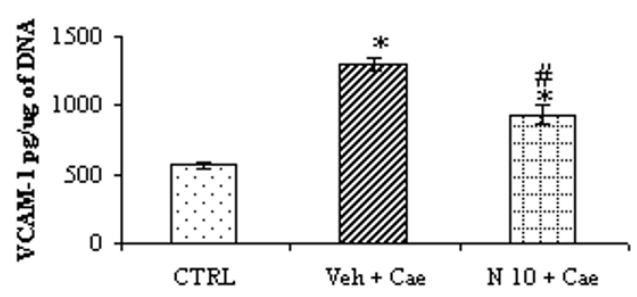

\section{Pulmonary adhesion molecules}

\author{
E-selectin
}

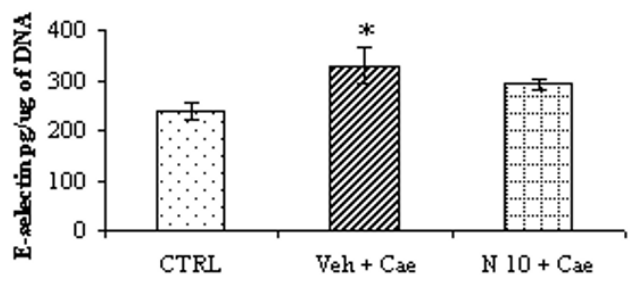

P-selectin

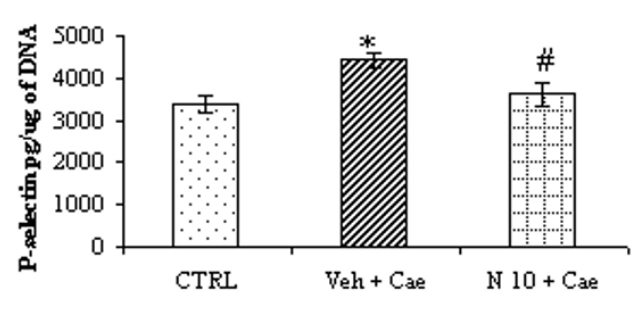

ICAM-1

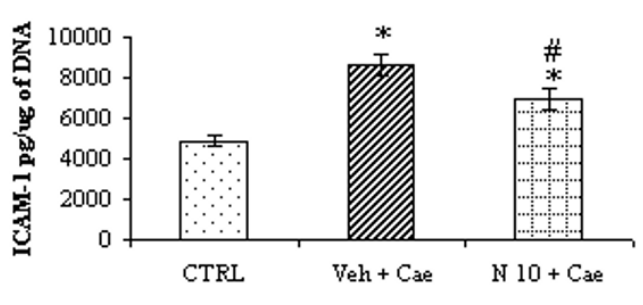

VCAM-1

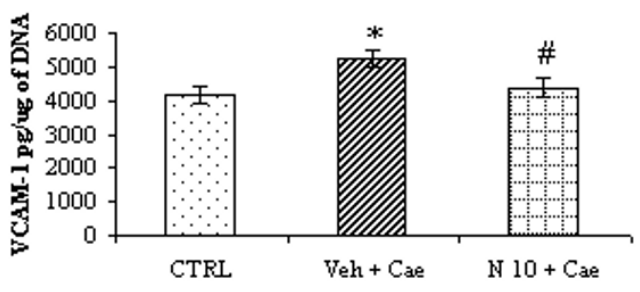

\section{Figure 5}

Effect of NaHS treatment on pancreatic and pulmonary adhesion molecules. Acute pancreatitis was induced by intraperitoneal administration of caerulein $((50 \mu \mathrm{g} / \mathrm{kg}$ hourly, for $10 \mathrm{~h})$. Column labeled 'CTRL' refers to adhesion molecules level in mice injected intraperitoneal saline (not caerulein) as control. Column labeled 'Veh+Cae' and 'NI0+Cae' refers pretreatment with vehicle or NaHS $(10 \mathrm{mg} / \mathrm{kg})$ administered intraperitoneal I h before the first injection of caerulein. Results shown are the mean \pm SEM for $8-10$ animals in each group. Asterisk $\left(^{*}\right)$ : $P<0.05$ c.f. control (saline) group. Asterisk $(\#)$ : $P<$ 0.05 c.f. (Veh + Cae) group. Abbreviations used: CTRL: Control; Cae: Caerulein; Veh: Vehicle; N: NaHS. 
ines such as CXCL1. CCL2 and CCL3 exert strong chemoattractant effects on monocytes, macrophages, and lymphocytes. Recent studies have suggested that CCL2 is an important inflammatory mediator during the early pathophysiological process of AP and promotes distant organ failure [20]. CXCL1 is a potent chemoattractant for polymorphonuclear neutrophils (PMN) and induces neutrophil degranulation and release of lysozyme, leading to tissue damage. We found that our treatment with NaHS $10 \mathrm{mg} / \mathrm{kg}$ was associated with significant reduction of pancreatic CCL2, CCL3 and CXCL1 as well as pulmonary CCL2 and CXCL1 (Fig. 4). However there was no change in pulmonary CCL3 with NaHS treatment (Fig. 4).

We also studied the effect of NaHS on the expression of adhesion molecules in pancreas and lung. Substantial evidence indicates that adhesion molecule expression is crucial to the development and modulation of inflammatory and immune processes. Vascular adhesion molecules are important component in leukocyte rolling, adhesion and trans-endothelial migration of inflammatory cells to the site of tissue injury $[19,21,22]$. ICAM-1, VCAM-1, E-selectin and P-selectin have been found to play an important pro-inflammatory role in various models of acute pancreatitis $[23,24]$. In present study of acute pancreatitis also, there was a significant increase of ICAM-1, VCAM-1, Eselectin and P-selectin in mice pretreated with vehicle confirming their pro-inflammatory role, while pretreatment with NaHS $10 \mathrm{mg} / \mathrm{kg}$ caused significant reduction of pancreatic ICAM-1, VCAM-1, E-selectin and P-selectin as well as pulmonary ICAM-1, VCAM-1 and P-selectin (Fig. $5)$. There was no change in pulmonary E-selectin level with NaHS pretreatment (Fig. 5) like pulmonary CCL3 (Fig. 4). These could be due to differential regulation of inflammatory responses mediated by NaHS in pancreas and lung.

\section{Conclusions}

In conclusion in this study of acute pancreatitis induced by hourly caerulein administration, pretreatment by different dosages of NaHS $(5 \mathrm{mg} / \mathrm{kg}, 10 \mathrm{mg} / \mathrm{kg}$ and $15 \mathrm{mg} /$ $\mathrm{kg}$ ) revealed that $\mathrm{NaHS} 10 \mathrm{mg} / \mathrm{kg}$ was associated with down-regulation of inflammation both in pancreas and lung and it was accompanied by reduction of pro-inflammatory chemokines and adhesion molecules. In addition, these results have further demonstrated dose dependent effects of NaHS in inflammation and thus confirm hydrogen sulfide as a novel gaseous transmitter that exerts dual effects in various pathophysiological conditions. Thus, an $\mathrm{H}_{2}$ S-releasing compound, at low doses, may represent a potential pharmacological approach in the treatment of inflammation. A lot of research is on going to develop novel $\mathrm{H}_{2} \mathrm{~S}$ donors and this line of research would, hopefully, provide a better solution to fight against the inflammatory disorders.

\section{Abbreviations}

$\mathrm{H}_{2} \mathrm{~S}$ : Hydrogen sulfide; NaHS: Sodium hydrosulfide; MPO: Myeloperoxidase; CBS: Cystathionine $\beta$-synthetase; CSE: Cystathionine $\gamma$-lyase; PAG: DL-propargylglycine; TMB: tetramethylbenzidine; ELISA: Enzyme-linked immunosorbent assay; CCL2: Chemokine (C-C motif) Ligand 2; CCL3: Chemokine (C-C motif) Ligand 3; CXCL1: Chemokine (C-X-C motif) Ligand 1; ICAM: Intercellular Cell Adhesion Molecule-1; VCAM-1: Vascular Cell Adhesion Molecule-1; NO: Nitric oxide; CO: Carbon monoxide; CVS: Cardiovascular system; CNS: Central nervous system; PMN: Polymorphonuclear neutrophils.

\section{Competing interests}

The authors declare that they have no competing interests.

\section{Authors' contributions}

JNS designed the study and it was approved by MB. JNS and SWN conducted animal experiments and did the plasma amylase, MPO assay, histology and ELISA. MB supervised all the experiments. JNS wrote the manuscript and $\mathrm{MB}$ reviewed and edited the manuscript. All authors read and approved the final manuscript.

\section{Acknowledgements}

This work was supported by the Biomedical Research Council of Singapore (grant number: R-184-000-094-305).

\section{References}

I. Moore PK, Bhatia M, Moochhala S: Hydrogen sulfide: from the smell of the past to the mediator of the future? Trends Pharmacol Sci 2003, 24:609-6II.

2. Szabó C: Hydrogen sulphide and its therapeutic potential. Nat Rev Drug Discov 2007, 6:917-935.

3. Bhatia M, Sidhapuriwala J, Moochhala SM, Moore PK: Hydrogen sulphide is a mediator of carrageenan-induced hindpaw oedema in the rat. Br J Pharmacol 2005, I45:|4|-I44.

4. Bhatia M, Wong FL, Fu D, Lau HY, Moochhala SM, Moore PK: Role of hydrogen sulfide in acute pancreatitis and associated lung injury. FASEB J 2005, 19:623-625.

5. Zhang $H$, Zhi L, Moore PK, Bhatia M: Role of hydrogen sulfide in cecal ligation and puncture-induced sepsis in the mouse. Am J Physiol Lung Cell Mol Physiol 2006, 290:LI I93-I20I.

6. Li L, Bhatia M, Zhu YZ, Zhu YC, Ramnath RD, Wang ZJ, Anuar FB, Whiteman M, Salto-Tellez M, Moore PK: Hydrogen sulfide is a novel mediator of endotoxic shock. FASEB J 2005, 19:1 196-II98.

7. Collin M, Anuar FB, Murch O, Bhatia M, Moore PK, Thiemermann C: Inhibition of endogenous hydrogen sulfide formation reduces the organ injury caused by endotoxemia. $\mathrm{Br} J$ Pharmacol 2005, 146:498-505.

8. Mok YY, Atan MS, Yoke Ping C, Zhong Jing W, Bhatia M, Moochhala $S$, Moore PK: Role of hydrogen sulphide in haemorrhagic shock in the rat: protective effect of inhibitors of hydrogen sulphide biosynthesis. $\mathrm{Br} J$ Pharmacol 2004, I 43:88I-889.

9. Sidhapuriwala J, Li L, Sparatore A, Bhatia M, Moore PK: Effect of Sdiclofenac, a novel hydrogen sulfide releasing derivative, on carrageenan-induced hindpaw oedema formation in the rat. Eur J Pharmacol 2007, 569:149-154.

10. Bhatia M, Sidhapuriwala JN, Sparatore A, Moore PK: Treatment with $\mathrm{H}_{2}$ S-releasing diclofenac protects mice against acute pancreatitis-associated lung injury. SHOCK 2008, 29:84-88.

II. Li L, Rossoni G, Sparatore A, Lee LC, Del Soldato P, Moore PK: Antiinflammatory and gastrointestinal effects of a novel diclofenac derivative. Free Radic Biol Med 2007, 42:706-719. 
12. Fiorucci S, Orlandi S, Mencarelli A, Caliendo G, Santagada V, Distrutti E, Santucci L, Cirino G, Wallace JL: Enhanced activity of a hydrogen sulphide releasing derivative of mesalamine (ATB-429) in a mouse model of colitis. Br J Pharmacol 2007, I 50:996- 1002.

13. Zanardo RC, Brancaleone V, Distrutti E, Fiorucci S, Cirino G, Wallace $\mathrm{JL}$ : Hydrogen sulfide is an endogenous modulator of leukocyte-mediated inflammation. FASEB J 2006, 20:21 I8-2I 20.

14. Esechie A, Kiss L, Olah G, Horváth EM, Hawkins H, Szabo C, Traber $D L$ : Protective effect of hydrogen sulfide in a murine model of acute lung injury induced by combined burn and smoke inhalation. Clin Sci (Lond) 2008, I I 5:91-97.

15. Sivarajah A, Collino M, Yasin M, Benetti E, Gallicchio M, Mazzon E, Cuzzocrea S, Fantozzi R, Thiemermann C: Anti-apoptotic and anti-inflammatory effects of hydrogen sulfide in a rat model of regional myocardial I/R. SHOCK 2009, 31:267-274.

16. Elrod JW, Calvert JW, Morrison J, Doeller JE, Kraus DW, Tao L, Jiao X, Scalia R, Kiss L, Szabo C, Kimura H, Chow CW, Lefer DJ: Hydrogen sulfide attenuates myocardial ischemia-reperfusion injury by preservation of mitochondrial function. Proc Natl Acad Sci USA 2007, 104:15560-15565.

17. Ji Y, Pang QF, Xu G, Wang L, Wang JK, Zeng YM: Exogenous hydrogen sulfide postconditioning protects isolated rat hearts against ischemia-reperfusion injury. Eur J Pharmacol 2008, 587:I-7.

18. Labarca C, Paigen K: A simple, rapid, and sensitive DNA assay procedure. Anal Biochem 1980, 102:344-352.

19. Bhatia M, Wong FL, Cao Y, Lau HY, Huang J, Puneet P, Chevali L: Pathophysiology of acute pancreatitis. Pancreatology 2005, 5:132-144.

20. Rau B, Baumgart K, Kruger CM, Schilling M, Beger HG: CC-chemokine activation in acute pancreatitis: enhanced release of monocyte chemoattractant protein- $I$ in patients with local and systemic complications. Intensive Care Med 2003, 29:622-629.

21. Carlos TM, Harlan JM: Leukocyte endothelial adhesion molecules. Blood 1994, 84:2068-2101.

22. Petri B, Phillipson M, Kubes P: The physiology of leukocyte recruitment: an in vivo perspective. J Immunol 2008, 1 80:6439-6446.

23. Frossard JL, Saluja A, Bhagat L, Lee HS, Bhatia M, Hofbauer B, Steer ML: The role of intercellular adhesion molecule $I$ and neutrophils in acute pancreatitis and pancreatitis-associated lung injury. Gastroenterology 1999, I I6:694-701.

24. Lau HY, Bhatia M: Effect of CP-96,345 on the expression of adhesion molecules in acute pancreatitis in mice. Am J Physiol Gastrointest Liver Physiol 2007, 2:GI283-I 292.

Publish with Bio Med Central and every scientist can read your work free of charge

"BioMed Central will be the most significant development for disseminating the results of biomedical research in our lifetime. "

Sir Paul Nurse, Cancer Research UK

Your research papers will be:

- available free of charge to the entire biomedical community

- peer reviewed and published immediately upon acceptance

- cited in PubMed and archived on PubMed Central

- yours - you keep the copyright
BioMedcentral 